\title{
Skrining Senyawa Antibakteri dari Beberapa Jenis Rumput Laut Coklat (Phaeophyceae) dari Pantai Drini, Daerah Istimewa Yogyakarta
}

\author{
Screening of Antibacterial Compounds from Several Brown Seaweeds (Phaeophyceae) \\ from Drini Beach, Yogyakarta
}

\author{
Boy R. Sidharta*, P. Kianto Atmodjo, E. Mursyanti \\ Fakultas Teknobiologi Universitas Atma Jaya Yogyakarta, Jl. Babarsari 44 Yogyakarta 55281 \\ E-mail: brsidharta@mail.uajy.ac.id*Penulis untuk korespondensi
}

\begin{abstract}
This present research was trying to determine the antibacterial compounds from several brown seaweeds from Drini beach. Previous studies have shown that several seaweeds from this beach were proved to have antibacterial activities. Therefore, it needs to be studied whether the extracts of several brown seaweeds utilizing three (3) kinds of extraction solutions such as aquadest, ethanol, and hexane, will also show antibacterial activities. The three solutions were chosen based on the difference of polarization activities. Research design utilized was randomized complete block design and the data compiled was treated by Anova and followed with Duncan's Multiple Range Test (DMRT) with degree of confidence 95\%. Microbes utilized in this research were Escherichia coli and Bacillus subtilis, that were common pathogenic bacteria known to human and animals. The research found six (6) species of brown seaweed during the research period, i.e. Sargassum dotyi, S. ohnoi, S. abbottiae, S. bataanense, Caulerpa prolifera, and Laurencia papillosa. This present research also revealed that ethanol was the best extraction solution to extract the secondary metabolite from the brown seaweeds found. The best antibacterial activities was shown by $S$. dotyi extract's to inhibit the two (2) microbes used in the research compared to other seaweed extracts. However, this result was still low and significantly different compare to pure antibiotics utilized, i.e. penicillin and streptomycin.
\end{abstract}

Key words: antibacterial compunds, brown seaweeds, extraction method

Diterima: 06 November 2007, disetujui: 07 Januari 2008

\section{Pendahuluan}

Penduduk Jepang dan Cina sejak jaman dulu telah menggunakan rumput laut sebagai obat, misalnya untuk penyakit gondong (goiter). Bahkan dalam "buku" tata cara pengobatan masyarakat Cina kuno, rumput laut telah dimanfaatkan untuk berbagai jenis penyakit seperti sakit perut saat menstruasi, abses (luka), doopsy, dan kanker (Ruggieri, 1976). Saat ini rumput laut telah dimanfaatkan oleh manusia di berbagai segi kehidupannya, mulai dari makanan sampai kesehatan (Anonim, 2004).

\begin{abstract}
Akhir-akhir ini penelitian rumput laut telah memasuki tahapan penerapan bioteknologi, antara lain dengan pengujian terhadap ekstrak atau kandungan metabolit sekunder-nya. Hal ini sangat beralasan karena ekstrak rumput laut tidak saja mengandung agar atau karaginan, yakni bahan-bahan yang telah dikenal sejak lama, tetapi juga mengandung bahan obat, yakni antibiotik atau antibakteri (Ruggieri, 1976).

Penelitian pendahuluan memperlihatkan bahwa ekstrak empat (4) jenis rumput laut hijau (Chlorophyceae) dari pantai Drini memiliki daya hambat terhadap bakteri patogen Bacillus subtilis dan Eschericia coli (Sidharta,
\end{abstract}


2003). Ekstrak rumput laut coklat jenis Sargassum sp yang didapat di Pantai Wediombo, Gunung Kidul, juga memperlihatkan kemampuan antibakteri yang cukup baik, yakni terhadap Escherichia coli dan Staphylococcus aureus (Pusparajasa, 2006).

Penelitian semacam ini tetap perlu dilakukan mengingat masih belum banyak yang diketahui dari kandungan atau ekstrak rumput laut, utamanya dari jenis rumput laut coklat (Phaeophyceae) di kawasan pesisir selatan DIY. Berbagai jenis rumput laut yang tumbuh di sepanjang pesisir selatan DIY saat ini hanya dimanfaatkan atau dipanen untuk dijual tanpa pengolahan terlebih dahulu, sehingga tidak memberi nilai jual (nilai tambah) bagi para nelayan. Perlu ada eksplorasi ilmiah lebih mendalam agar dapat memberi manfaat bagi nelayan setempat. Hasil dari penelitian ini nantinya diharapkan dapat memberikan informasi kepada semua pihak yang hendak membangun dan mengembangkan kawasan pesisir selatan DIY, khususnya di bidang industri farmasi.

Sebagian besar rumput laut dijumpai di kawasan tropis dan teragihkan secara meluas di daerah paparan benua (continental shelf) (Paul dan Fenical, 1987). Sudah banyak jenis rumput laut yang digunakan oleh manusia. Di Indonesia beberapa jenis rumput laut dimanfaatkan sebagai bahan makanan dan penghasil agar seperti Gelidium spp, Gracilaria spp, Sargassum spp, Eucheuma spp, dan lainlain (Hatta dan Purnomo, 1994).

Daya antibiotik pada rumput laut telah dilaporkan oleh beberapa peneliti, misalnya alga coklat Ascophyllum nodosum dapat terbebas dari mikroorganisme yang biasanya menempel pada thalus dan menjadi parasit bagi rumput laut. Penelitian lebih lanjut pada rumput laut tersebut berhasil diperoleh senyawa metabolit sekunder yakni asam akrilat (acrylic acid) yang memiliki kemampuan antibiotik. Jenis rumput laut lainnya, Sargassum natans, menghasilkan senyawa sarganin yang sangat efektif untuk menghambat pertumbuhan bakteri Gram negatif (Sieburth, 1990).

Metabolit sekunder yang diekstrak dari beberapa biota laut pada umumnya dicirikan dengan keunikan kandungan senyawanya, yaitu dari golongan terpenoid (Fenical, 1982). Metabolit semacam itu sangat khas dan berbeda jauh dengan metabolit yang dihasilkan oleh biota daratan, karena metabolit sekunder biota laut kaya akan kandungan unsur halida dan berat molekulnya lebih tinggi (C-20) (Paul dan Fenical, 1987). Para ahli menduga bahwa metabolit sekunder yang dihasilkan oleh biota laut tadi dimaksudkan sebagai mekanisme pertahanan diri terhadap predator mereka (Ruggieri, 1976; Fenical, 1982; Paul dan Fenical, 1987).

Pada masa-masa belakangan ini kegiatan fisiologis rumput laut, khususnya yang terkait dengan produksi metabolit sekundernya, menjadi fokus berbagai penelitian. Beberapa penelitian di bidang ini telah mengarah pada pemerolehan senyawa-senyawa "baru" yang memiliki kemampuan farmakologis, terutama obat dari golongan antibakteri (de Val et al., 2001).

Berbagai metode ekstraksi untuk mendapatkan senyawa bioaktif dalam bagian tubuh tumbuhan darat telah banyak dikembangkan (Setyawati et al., 2002; Dwiati dan Budisantoso, 2005; Elfita et al., 2005; Rustama et al., 2005), demikian pula untuk biota laut (de Val et al., 2001; Lima-Filho et al., 2002; Sidharta, 2003; Astuti et al., 2003). Larutan pengekstrak yang digunakan untuk tujuan tersebut, umumnya dengan pertimbangan tingkat polaritas, yakni mulai dari tingkat polaritas paling rendah (misalnya heksan) sampai tingkat polaritas tertinggi (air/akuades) (Sudarmadji, 1996). Pemilihan larutan pengekstrak juga menarik untuk dikaji secara terus-menerus, termasuk dalam hal mengekstrak senyawa metabolit sekunder dalam rumput laut.

\section{Metode Penelitian}

Penelitian ini dilaksanakan dalam 2 (dua) tahapan. Tahap Pertama meliputi pengambilan sampel berbagai rumput laut coklat di pantai Drini, Gunung Kidul, DIY. Beberapa jenis rumput laut yang diperoleh kemudian diinventarisasi dan diidentifikasi didasarkan atas kajian Trono, Jr (2004). 
Selanjutnya (Tahap Kedua) sampel rumput laut yang sama diambil dalam keadaan basah dan segar masing-masing sebanyak $2 \mathrm{~kg}$ agar didapat cukup sampel kering. Sampel rumput laut dimasukkan ke dalam kantongkantong plastik serta diberi label (yang berisi kode, nama daerah, nama ilmiah, dan nomor sampel) dan selanjutnya disimpan di dalam kotak pendingin (ice box) agar suhu air dapat dijaga. Sesampai di laboratorium, sampel dicuci dengan air tawar beberapa kali, kemudian dipotong-potong untuk memudahkan proses selanjutnya. Potongan-potongan rumput laut dimasukkan ke dalam blender untuk dihaluskan dan setelah halus sampel dikeringanginkan di bawah sinar matahari. Sampel kering diekstraksi dengan menggunakan 3 (tiga) senyawa pelarut dengan berbagai tingkatan polaritas yaitu: heksan, etanol, dan air/aquades (Henriques et al., 1979; Sudarmadji, 1996). Pada tahap kedua, masingmasing hasil ekstraksi dilakukan skrining atau pengujian sifat antibiotiknya dengan menggunakan 2 (dua) jenis bakteri yang bersifat patogen terhadap manusia, seperti Bacillus subtilis dan Eschericia coli. Kedua jenis mikrobia tersebut diperoleh dari koleksi yang ada di Laboratorium Teknobio-Industri, Fakultas Teknobiologi Universitas Atma Jaya Yogyakarta. Kemampuan antibakteri dari masing-masing ekstrak diuji lebih lanjut dengan cara membandingkan daya hambatnya dengan 2 (dua) antibiotik yang umum digunakan di bidang medis/kesehatan, yaitu penisilin dan streptomisin. Aktivitas daya hambat dilakukan dengan memakai metode cawan agar dengan konsentrasi sebesar 0,10 mg/keping. Zona penghambatan yang terbentuk kemudian diukur. Analisis statistik berupa ANOVA digunakan sedang untuk mengetahui beda nyata antar perlakuan diterapkan Duncan's Multiple Range Test (DMRT) dengan tingkat kepercayaan $95 \%(\alpha=5 \%)$.

\section{Hasil dan Pembahasan}

\section{Rumput laut coklat yang diperoleh}

Sampel rumput laut diambil pada saat air laut surut, sehingga memudahkan pengambilan sampel rumput laut. Pengambilan rumput laut dilakukan tanpa menggunakan alat, dicabut langsung dari substratnya. Hal ini dimaksudkan agar tidak merusak habitat alami rumput laut tersebut serta tetap memberikan kesempatan agar rumput laut dapat terus tumbuh dan berkembang biak di tempat asalnya.

Kebiasaan masyarakat setempat biasanya memanen rumput laut dengan cara "mengerok" sampai ke akar-akarnya dengan menggunakan alat semacam pisau (Suharni et al., 1990). Praktek semacam ini tentu akan menyebabkan ancaman terhadap keberadaan rumput laut serta menimbulkan kesulitan bagi rumput laut untuk berkembang biak dengan cepat di habitat tersebut.

Beberapa jenis rumput laut coklat yang didapat diidentifikasi berdasarkan penelitian Trono, Jr. (2004) dan hasilnya tercantum dalam Gambar 1 dan Tabel 1.

\section{Uji antibakteri ekstrak rumput laut}

Uji antibakteri ekstrak keenam rumput laut coklat yang didapat dirangkum dalam Tabel 2. Hasil uji memperlihatkan variasi kemampuan antibakteri senyawa metabolit sekunder yang diekstrak dengan berbagai senyawa penyari yang digunakan.

Penyari etanol menunjukkan hasil uji ekstrak keenam rumput laut yang memiliki sifat antibakteri tertinggi dibandingkan dengan kedua penyari lainnya (Tabel 2). Zona hambat terluas didapat pada sampel rumput laut Sargassum dotyi, baik untuk mikrobia uji $B$. subtilis maupun $E$. coli, masing-masing dengan luas zona hambat sebesar 2,298 dan 12,213 $\mathrm{mm}^{2}$. Bila dibandingkan dengan perlakuan antibiotik murni yang biasa digunakan di pasaran yakni penisilin dan streptomisin, hasil tersebut berbeda secara signifikan. Hasil penelitian Pusparajasa (2006) dengan mengekstrak rumput laut Sargassum sp dengan penyari eter dan akuades juga memperlihatkan hasil yang tidak jauh berbeda pada mikrobia uji E. coli dan Staphylococcus aureus.

Penyari heksan dan akuades yang digunakan dalam penelitian tidak memperlihatkan hasil yang diharapkan. Bahkan dari beberapa sampel ekstrak tidak didapati adanya daya hambat terhadap mikrobia uji. Misalnya pada ekstrak akuades S. dotyi terhadap kedua mikrobia uji tidak diperoleh 
adanya penghambatan terhadap kedua mikrobia uji. Demikian pula ekstrak akuades rumput laut C. prolifera. Hal yang sama didapatkan pada ekstrak penyari heksan untuk rumput laut $S$. abbottiae, S. bataanense dan L. papillosa (Tabel 2). Perbedaan hasil uji ekstrak antarpenyari sangat dipengaruhi oleh sifat penyari yang dipergunakan dan sifat senyawa metabolit sekunder dalam rumput laut. Perbedaan ketiga penyari yang dipakai dalam penelitian didasarkan pada perbedaan polaritasnya, yaitu heksan sebesar 1,89, etanol 24,3 dan akuades 78,3 (Sudarmadji, 1996). Angka polaritas tertinggi pada akuades, misalnya, tidak berarti akan menghasilkan ekstrak dengan sifat antibakteri yang diharapkan. Hal ini berlaku hukum "solve dissolve like". Kemampuan penyari etanol, dengan demikian, memperlihatkan potensi yang paling baik untuk menyarikan senyawa metabolit sekunder yang terdapat di dalam thallus rumput laut Sargassum dotyi.

Tabel 1. Beberapa jenis rumput laut coklat yang diperoleh

\begin{tabular}{|c|c|c|}
\hline No. & "Nama Jenis & "Keterangan \\
\hline 1. & Sargassum dotyi & $\begin{array}{l}\text { thallus berwarna coklat kehijauan, thallus dapat sangat panjang, daun } \\
\text { bergerigi terletak menyebar sepanjang thallus, ukuran daun panjang } \pm 3 \mathrm{~cm} \\
\text { dan lebar } \pm 2 \mathrm{~cm} \text {, perlekatan thallus ke substrat dengan rizoid yang } \\
\text { berbentuk diskus, ukuran vesikel (bola udara) kecil dengan diameter } \pm 1 \mathrm{~cm}\end{array}$ \\
\hline 2. & Sargassum abbottiae & $\begin{array}{l}\text { thallus berwarna coklat kehijauan, daun berbentuk bulat-lonjong } \\
\text { bergerombol di sepanjang thallus, perlekatan dengan rizoid, ukuran vesikel } \\
\pm 3 \mathrm{~mm} \text {, permukaan thallus terlihat semacam "duri-duri" }\end{array}$ \\
\hline 3. & Sargassum ohnoi & $\begin{array}{l}\text { thallus berwarna coklat kehijauan, bagian ujung daun terdapat } \\
\text { percabangan, ukuran bola udara berkisar } 0,5-1 \mathrm{~cm} \text { dengan tangkai yang } \\
\text { melekat di ketiak daun }\end{array}$ \\
\hline 4. & Sargassum bataanense & $\begin{array}{l}\text { thallus berwarna coklat, daun bergerombol memadat sepanjang thallus, } \\
\text { ukuran panjang daun } \pm 5 \mathrm{~cm} \text { dan lebar } \pm 1-2 \mathrm{~cm} \text {, perlekatan dengan substrat } \\
\text { menggunakan rizoid yang berbentuk diskus } / \text { cakram }\end{array}$ \\
\hline 5. & Caulerpa prolifera & $\begin{array}{l}\text { thallus berwarna coklat dengan percabangan semu, "daun" berbentuk bulat } \\
\text { gilig dengan ukuran panjang }+8 \mathrm{~cm} \text { dan lebar }+1 \mathrm{~cm} \text {, perlekatan pada } \\
\text { substrat dengan rizoid berbentuk serabut }\end{array}$ \\
\hline 6. & Laurencia papillosa & $\begin{array}{l}\text { thallus berwarna coklat kehijauan, "daun" bergerombol padat menyerupai } \\
\text { bulatan-bulatan kecil di sepanjang thallus, perlekatan dengan substrat } \\
\text { dengan rizoid serabut }\end{array}$ \\
\hline
\end{tabular}

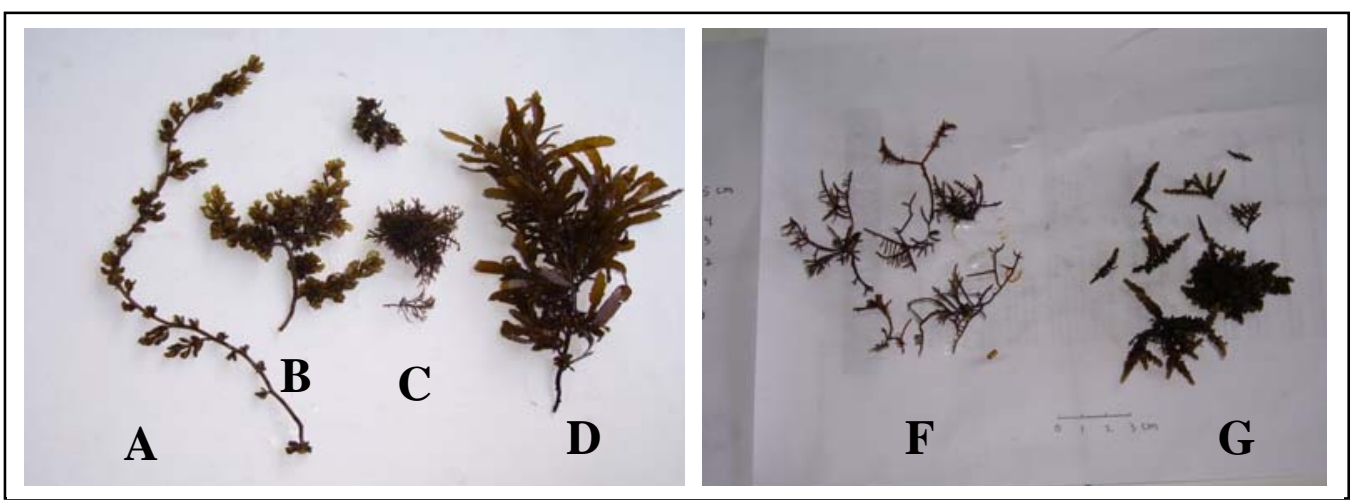

Gambar 1. Rumput laut coklat (A sampai F) yang diperoleh di Pantai Drini selama penelitian berlangsung.

Keterangan: A = Sargassum dotyi

$\mathrm{B}=$ S. abbottiae

$\mathrm{D}=\mathrm{S}$. bataanense

$\mathrm{C}=$ S. ohnoi

$\mathrm{E}=$ Caulerpa prolifera

$\mathrm{F}=$ Laurencia papillosa 
Peringkat kedua dalam hal "kekuatan" penghambatan terhadap mikrobia uji dicatat oleh ekstrak rumput laut Laurencia papillosa dengan penyari etanol, masing-masing diperoleh luas zona hambat untuk $B$. subtilis dan E. coli sebesar 1,917 dan $0,250 \mathrm{~mm}^{2}$. Berikutnya diikuti oleh ekstrak rumput laut Sargassum bataanense dengan luas zona hambat 1,805 dan $0,513 \mathrm{~mm}^{2}$, ekstrak rumput laut $S$. abbottiae dengan luas zona hambat 0 dan $1,133 \mathrm{~mm}^{2}$, ekstrak rumput laut Caulerpa prolifera dengan luas zona hambat 0,983 dan $0,811 \mathrm{~mm}^{2}$, dan ekstrak rumput laut $S$. ohnoi dengan luas zona hambat sebesar 0,080 dan $0,399 \mathrm{~mm}^{2}$ (Tabel 2).
Hasil di atas menunjukkan bahwa terdapat perbedaan antara satu jenis rumput laut dengan rumput laut lainnya dalam hal kandungan senyawa metabolit sekundernya. Bahkan di antara satu marga (genus) Sargassum, misalnya, diperoleh hasil yang tidak setara. Sargassum dotyi diperkirakan memiliki senyawa bioaktif antibakteri yang lebih baik daripada $S$. bataanense, S. abbottiae, dan S. ohnoi. Hal ini menjadi semakin berbeda di antara marga yang lainnya seperti pada Caulerpa dan Laurencia, yang secara genetis maupun ekologis sangat berbeda satu dengan lainnya (De Val et al., 2001; Lima-Filho et al., 2002).

Tabel 2. Luas zona hambat $\left(\mathrm{mm}^{2}\right)$ ekstrak rumput laut coklat terhadap bakteri uji

\begin{tabular}{|c|c|c|c|}
\hline Macam Perlakuan & Jenis Senyawa & Bacillus subtilis & Escherichia coli \\
\hline \multirow{3}{*}{ Sargassum dotyi } & aquades & $0^{\mathrm{a}}$ & $0^{\mathrm{a}}$ \\
\hline & etanol & $2,298^{\mathrm{h}}$ & $12,213^{\mathrm{j}}$ \\
\hline & heksan & $0,002^{\mathrm{a}}$ & $0^{\mathrm{a}}$ \\
\hline \multirow{3}{*}{ S. abbottiae } & aquades & $0,049^{b}$ & $0^{\mathrm{a}}$ \\
\hline & etanol & $0^{\mathrm{a}}$ & $1,133^{\mathrm{f}}$ \\
\hline & heksan & $0^{\mathrm{a}}$ & $0^{\mathrm{a}}$ \\
\hline \multirow{3}{*}{ S. ohnoi } & aquades & $0^{\mathrm{a}}$ & $0,014^{\mathrm{a}}$ \\
\hline & etanol & $0,080^{\mathrm{b}}$ & $0,399^{\mathrm{c}}$ \\
\hline & heksan & $0,005^{\mathrm{a}}$ & $0,011^{\mathrm{a}}$ \\
\hline \multirow{3}{*}{ S. bataanense } & aquades & $0,017^{\mathrm{a}}$ & $0,889^{\mathrm{e}}$ \\
\hline & etanol & $1,805^{\mathrm{g}}$ & $0,513^{\mathrm{d}}$ \\
\hline & heksan & $0^{\mathrm{a}}$ & $0^{\mathrm{a}}$ \\
\hline \multirow{3}{*}{ Caulerpa prolifera } & aquades & $0^{\mathrm{a}}$ & $0^{\mathrm{a}}$ \\
\hline & etanol & $0,983^{\mathrm{f}}$ & $0,811^{\mathrm{e}}$ \\
\hline & heksan & $0,600^{\mathrm{d}}$ & $0^{\mathrm{a}}$ \\
\hline \multirow{3}{*}{ Laurencia papillosa } & aquades & $0^{\mathrm{a}}$ & $0,461^{\mathrm{c}}$ \\
\hline & etanol & $1,917^{\mathrm{g}}$ & $0,250^{\mathrm{b}}$ \\
\hline & heksan & $0^{\mathrm{a}}$ & $0^{\mathrm{a}}$ \\
\hline \multirow[t]{3}{*}{ Kontrol-1 } & aquades & $0,524^{\mathrm{d}}$ & $0^{\mathrm{a}}$ \\
\hline & etanol & $3,140^{\mathrm{i}}$ & $3,140^{\mathrm{i}}$ \\
\hline & heksan & $1,395^{\mathrm{f}}$ & $0,348^{\mathrm{c}}$ \\
\hline \multirow[t]{2}{*}{ Kontrol-2 } & penicillin & $63,585^{1}$ & $31,487^{\mathrm{K}}$ \\
\hline & streptomycin & $106,850^{\mathrm{m}}$ & $192,670^{\mathrm{n}}$ \\
\hline
\end{tabular}

Keterangan: Data merupakan rerata dari 18 kali ulangan. Huruf yang sama menunjukkan tidak ada perbedaan signifikan antardata dalam kolom dan baris dengan tingkat kepercayaan 95\%

\section{Kesimpulan dan Saran}

\section{Kesimpulan}

Penelitian ini mendapatkan simpulan bahwa: ditemukan 6 (enam) spesies rumput laut coklat selama periode penelitian. Keenam spesies tersebut adalah: Sargassum dotyi, $S$. abbottiae, S. ohnoi, S. bataanense, Caulerpa prolifera, dan Laurencia papillosa. Senyawa pengekstrak yang terbaik untuk "menarik" senyawa metabolit sekunder di dalam sampel rumput laut coklat adalah etanol. Sifat antibakteri ekstrak sampel rumput laut Sargassum dotyi memperlihatkan daya hambat yang paling kuat dibandingkan dengan sampel rumput laut lainnya. Tidak didapatkan hasil yang signifikan antara ekstrak sampel rumput laut dengan kontrol berupa antibiotik penisilin dan streptomisin. 


\section{Saran}

Hasil penelitian ini seyogyanya dilanjutkan dengan penelitian terapan yang bertujuan untuk memurnikan ekstrak rumput laut yang memiliki sifat antibakteri dengan menerapkan metode separasi berdasarkan perbedaan ukuran molekul senyawa aktif dan dilakukan ujicoba secara farmakologis serta klinis pada hewan uji yang terinfeksi bakteri. Selain itu, penggunaan senyawa penyari dengan berbagai tingkat polaritas dan variasi lama waktu maserasi perlu dilakukan dalam penelitian selanjutnya.

\section{Ucapan Terima Kasih}

Para peneliti mengucapkan terima kasih kepada pihak LPPM Universitas Atma Jaya Yogyakarta yang telah memberikan dukungan dana, sehingga penelitian ini dapat terlaksana. Penghargaan juga disampaikan kepada Sdri. Theresia Ani Riswati, S.Si dan Sdr. Leonardus, S.Si. yang telah membantu proses penelitian ini, serta kepada Sdr. Alb. Adirianto untuk dukungan teknis saat penelitian dilakukan di Lab. Teknobio Industri Fakultas Teknobiologi Universitas Atma Jaya Yogyakarta. Terima kasih secara khusus kepada pembaca (reviewer) naskah awal laporan penelitian ini.

\section{Daftar Pustaka}

Anonim. 2004. Rumput laut berpotensi menyumbang devisa Rp79,984 trilyun per tahun. KOMPAS, Senin, 04/19/2004, halaman 15.

Astuti, P., Alam, G., Pratiwi, S.U.T., Hertian, T. dan Wahyono, S. 2003. Skrining senyawa antiinfeksi dari spons yang dikoleksi dari Bunaken Manado. Biota 8 (2): 47-52.

De Val, A.G., Platas, G., Basilio, A., Cabello, A., Gorrochategui, J., Suay, I., Vicente, F., Portillo, E., del Rio, M.J., Reina, G.G. and Pelaez, F. 2001. Screening of antimicrobial activities in red, green, and brown macroalgae from Gran Canaria (Canary Islands, Spain). Int. Microbiol. 4: 35-40.

Dwiati, M. dan Budisantoso, I. 2005. Kandungan bahan aktif fomesafen dalam biji kedelai dan kacang tanah. Biosfera 22 (1): 12-17.

Elfita, Anwar, L. dan Ilham, A. 2005. Isolasi dan identifikasi senyawa utama fraksi aktif sitotoksis batang jambu kaliang (Eugenia cumini Bruce). J. Pen. Sain. 17: 1-9.

Fenical, W. 1982. Natural product chemistry in the marine environment. Science 215: 923-927.

Hatta, M. and Purnomo, A.H. 1994. Economic seaweed resources and their management in eastern Indonesia. NAGA Quarterly 17 (2): 1-3

Henriques, P., Candia, A., Norambuena, R., Silva, M. and Zemelman, R. 1979. Antibiotic properties of marine algae II. Screening of Chilean marine algae for antimicrobial activity. Botanica Marina 22: 451-453.

Lima-Filho, J.V., Carvalho, A.F.F.U., Freitas, S.M. and Melo, V.M.M. 2002. Antibacterial activity of extracts of six macroalgae from the northeastern Brazilian coast. Braz. J. Microbiol. 33 (4): 311-313.

Paul, V.J. and Fenical, W. 1987. Natural products chemistry and chemical defense in tropical marine algae of the phylum Chlorophyta. In: Scheuer, P.J. (Eds.). Bioorganic marine chemistry. I: 1-29. Springer-Verlag, Berlin.

Pusparajasa, A. 2006. Aktivitas antibakteri ekstrak Sargassum sp terhadap Eschericia coli dan Staphylococcus aureus dengan variasi pengekstrak. Skripsi. Fakultas Biologi, Universitas Atma Jaya Yogyakarta. Tidak Diterbitkan

Ruggieri, G.D. 1976. Drugs from the Sea. Marine organisms with Novel chemical constituents are excellent sources of new drugs. Science 194: 491-497.

Rustama, M.M., Rahayuningsih, S.R., Kusmono, J. dan Safitri, R. 2005. Uji aktivitas antibakteri ekstrak air dan etanol bawang putih (Allium sativum L) terhadap bakteri Gram positif dan negatif. Biotika 4 (2): 1-8.

Setyawati, T., Esyanti, R.R. dan Siregar, A.H. 2002. Analisis kandungan metabolit sekunder gosipol kultur akar kapas. BiotikaI(2): 16-21.

Sidharta, B.R. 2003. Screening of antibiosis activity from green algae (Chlorophyta) from Drini Beach, Yogyakarta: a Preliminary Study. Biota 8 (2): 53-58.

Sieburth, J.M. 1990. The influence of algal antibiosis on the ecology of marine microorganisms. An. Rev. Microb. 63-94.

Sudarmadji, S. 1996. Teknik Analisa Biokimiawi. Liberty, Yogyakarta. 332 halaman.

Suharni, Th., Sidharta, B.R., Mursyanti, E. dan Atmodjo, P.K. 1990. Upaya budidaya rumput laut di Pantai Drini DIY. Laporan Penelitian. LPPM Universitas Atma Jaya Yogyakarta. Tidak Diterbitkan.

Trono, Jr. 2004. Philippine's Seaweed Guide. BFAR and MSI-UP. 236 halaman. 


\section{Lampiran: Gambar zona hambat antibakteri ekstrak beberapa rumput laut coklat}
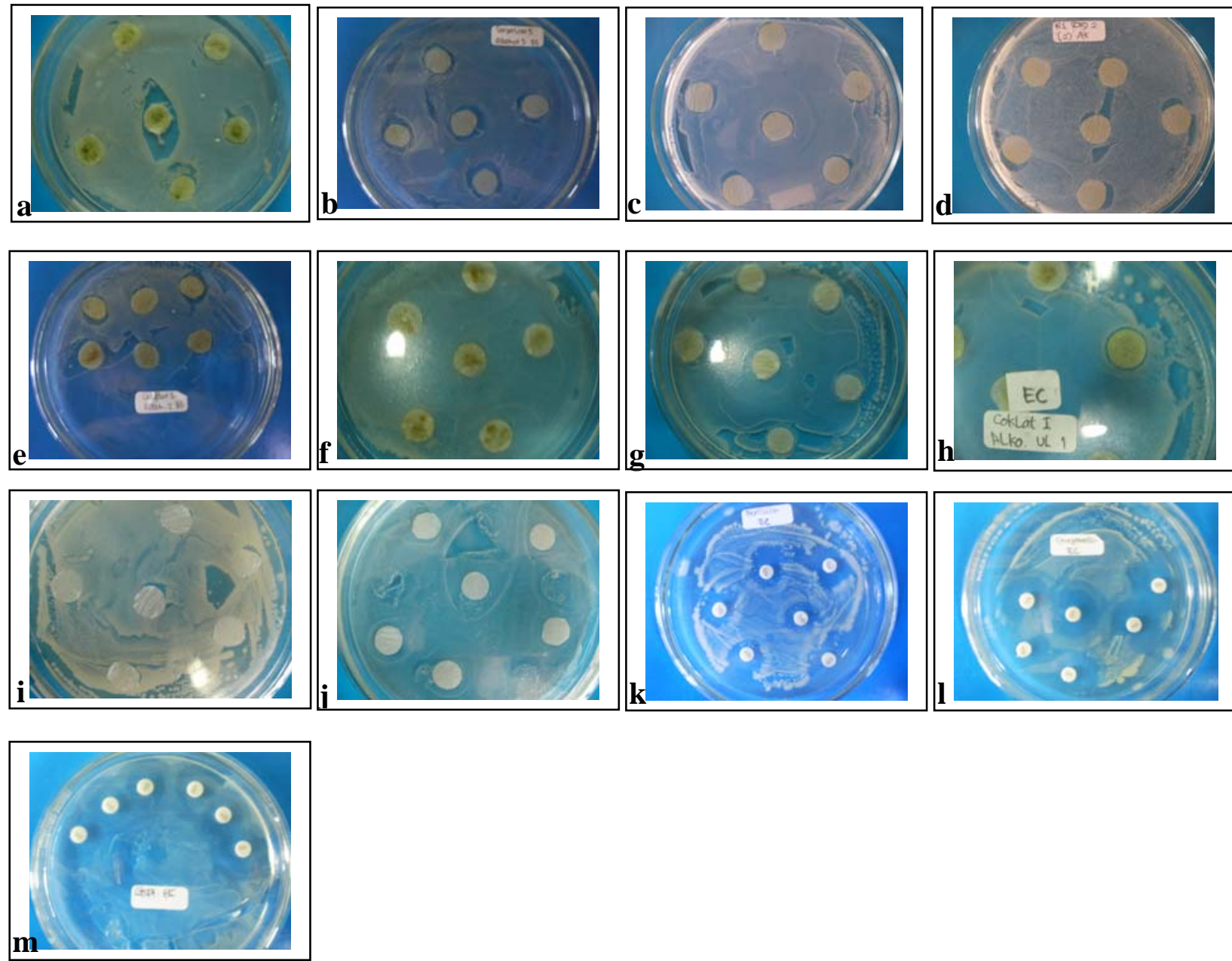

\section{Keterangan:}

a. Zona hambat ekstrak rumput laut Sargassum dotyi dalam etanol terhadap E. coli

b. Zona hambat ekstrak rumput laut Sargassum dotyi dalam heksan terhadap B. subtilis

c. Zona hambat ekstrak rumput laut Sargassum ohnoi dalam akuades terhadap E. coli

d. Zona hambat ekstrak rumput laut Sargassum ohnoi dalam etanol terhadap B.subtilis

e. Zona hambat ekstrak rumput laut Caulerpa sp dalam akuades terhadap E.coli

f. Zona hambat ekstrak rumput laut Laurencia sp dalam heksan terhadap B.subtilis

g. Zona hambat ekstrak rumput laut Caulerpa sp dalam etanol terhadap E. coli

h. Zona hambat ekstrak rumput laut Laurencia sp dalam akuades terhadap B.subtilis

i. Zona hambat ekstrak rumput laut Sargassum abbottiqe dalam etanol terhadap B.subtilis

j. Zona hambat penisilin terhadap E. coli

k. Zona hambat penisilin terhadap B. subtilis

1. Zona hambat streptomisin terhadap E. coli

m. Zona hambat streptomisin terhadap B. subtilis 